$\sqrt{3}$

J. Bio-Sci. 27: 133-141, 2019

ISSN 1023-8654

http://www.banglajol.info/index.php/JBS/index

DOI: https://doi.org/10.3329/jbs.v27i0.44678

\title{
INTERPHASE NUCLEAR PHENOTYPE AND CHROMOSOMAL VARIATION IN CYNODON DACTYLON (L.) PERS
}

\author{
SK Nitu1\&2, SMS Islam² ${ }^{*}$ and $\mathrm{H}$ Tarique ${ }^{3}$ \\ ${ }^{1}$ Department of Botany, University of Rajshahi, University of Rajshahi \\ 2Plant Biotechnology and Genetic Engineering Lab., Institute of Biological Sciences, University of Rajshahi \\ ${ }^{3}$ Department of Agronomy and Agriculture Extension, University of Rajshahi, Bangladesh
}

\begin{abstract}
Interphase nuclear phenotype in different accessions (Acc.) of Cynodon dactylon studied in the present experiment showed chromocentric nuclear organization and the chromocenters were found to be visible clearly. The chromocenter numbers were not same and sometimes it was found to be significantly less and never more than total number of chromosomes. Percentages of heterochromatin values were expressed per nuclear area and the values range from $19.759 \%$ (Acc. 16) to $66.022 \%$ (Acc.18). Nuclear volume as well as interphase chromosome volume was found to vary $0.674 \mu \mathrm{m}^{3}$ (Acc.6) to $41.921 \mu \mathrm{m}^{3}$ (Acc.10) and from $0.028 \mu \mathrm{m}^{3}$ (Acc. 6) to $1.905 \mu \mathrm{m}^{3}$ (Acc. 10), respectively. The somatic chromosome number found to vary from 12 to $40.2 n=18$ chromosomes were found in eight accessions of $C$. dactylon. Only one accession was found to be tetraploid and rest of them aneuploid whose chromosome numbers were $12,14,16,22,24,26,32,40$ etc. The availability of aneuploid shows great aspects of forage breeding programme.
\end{abstract}

Key words: Aneuploidy, Camera-lucida, Chromosome number, Cynodon dactylon, Interphase, Nuclear volume

\section{Introduction}

Cynodon dactylon (L.) Pers. (commonly known as Bermuda grass and locally as Durba) is a typical warmseason turfgrass belonging to Poaceae. This species is widely distributed in warm, humid and semi-arid areas around the Himalayas with excellent heat and drought tolerance capacity (Harlan et al. 1970, Dunne et al. 2019). This grass species is widely adapted to various environments of tropical and sub-tropical regions of the world and there are some ways for genetic diversity and population structure analysis of Bermudagrass (Zheng et al. 2017). Bermuda grass has attracted interest of plant scientists because of their ease of cultivation, high forage production and high nutritional value (Pedreira 1996). This species shows high growth rate, grazing resistance, high carrying capacity and rapid establishment (De Lima and Vilela 2005). Cytogenetic information like interphase nuclear phenotype and chromosomal characterization are very useful parameters in distinguishing the cytotypes, accessions (Acc.) and even germplasm of a plant species (Huang et al. 2014). The information on chromosome number of $C$. dactylon is limited to the determination of ploidy level. On the basis of previous research work, this species has the basic chromosome number $x=9$ (Dhaliwal and Gupta 2011, Zhi-Yun et al. 2013). However, this species has been reported with different

\footnotetext{
*Author for correspondence: shahinul68@gmail.com
} 
ploidy level such as triploid $(2 n=3 x=27)$, tetraploid $(2 n=4 x=36)$, few pentaploid $(2 n=5 x=45)$, and hexaploid $(2 n=6 x=54)$ according to Harlan et al. (1970) and Wu and Taliaferro (2009).

In contrast Hunter (1934), Hurcombe (1947), Moffett and Hurcombe (1948) and Rochecouste (1962) recorded different chromosome number such as $2 n=40$ for this species with probable basic number $x=10$. However, information on aneuploidy of this species is insufficient and it seems like that real differences in chromosome number along with variation might be related to ecological condition. Parvin (2002) reported aneuploidy in $C$. dactylon. Thus, the goal of this study was to discriminate the different accessions of $C$. dactylon collected from different ecological zones of Bangladesh.

There are two types of structural organization in plant cell nuclei and they are namely chromocentric and reticulate (Lafontaine 1974). Interphase nuclear phenotype of plants is species specific and indicates several important features regarding chromosomal arrangement (Patankar and Raujekar 1984). Its reasons are unknown although the role of nuclear DNA content and repetitive DNA sequence has been suggested to be associated with those features (Lafontaine 1974, Nagl and Fusenig 1979). They also suggested that chromocentric nuclear organization is assumed to be governed by small size of chromosomes and low DNA content. As chromocenters correspond to heterochromatin (Nagl and Fusenig 1979), percentage of heterochromatin values may be obtained by determining the area of nucleus and of chromocenters by planimetry (Kabir and Singh 1989). Keeping these points in mind interphase nuclear phenotype of $C$. dactylon accessions have been determined in this study along with interphase chromosome volume.

\section{Materials and Methods}

Cynodon dactylon were used as experimental material in the present study and at least ten plants of each accession these were collected from 19 different districts of Bangladesh. The materials were grouped into four different groups based on their growing area (habitat) as North, West, East and South zones and these were transplanted in the experimentation field of the Institute of Biological Science, University of Rajshahi, Bangladesh.

When these were grown well in the experimental field, their root tips (approximately $1-1.5 \mathrm{~cm}$ in length) were treated with saturated solution of paradichlorobenzene at $10^{\circ} \mathrm{C}$ in the refrigerator for $4-4.5 \mathrm{hrs}$. Then the root tips were washed with distilled water and fixed in 1:3 aceto-alchohol for 48 hrs at room temperature. After fixation they were washed again with distilled water, preserved in $70 \%$ ethanol and kept in the refrigerator for further uses. For cytological study, the root tip cells were stained with $0.5 \%$ haematoxylin according to the method of Haque et al. (1976). Stained meristematic zone was taken on a clean slide, squashed with a drop of $0.5 \%$ acetocarmine and a gentle pressure was applied by thumb over the cover glass. For chromosome counting, photomicrography was made from metaphase plate using $40 \times 10$ magnification and at the same time for clear visualization camera lucida drawings were made. For measuring Nuclear Volume (NV) from interphase, occulometer was used and the values were converted in micron $(\mu)$ with the help of stage micrometer, using the formula, NV $=4 / 3 \pi^{3}$ (Nayar et al. 1971). These values divided by somatic chromosome number gave the interphase chromosome volume. Chromocenters were counted and heterochromocentric values were determined by planimetry (add reference and mention the equation). 


\section{Results}

All the accessions of $C$. dactylon studied in the present experiment showed chromocentric nuclear organization. The chromocenters were seen distinctly on a very light background of the microscope and a few of the representative plates of interphase showing chromocentric structure are presented in Fig. A (1-9). The numbers of chromocenters for each accession are not corresponding with their somatic chromosome number. Sometimes it was found to be significantly less and obviously not more than their respective chromosome number. Percentage of heterochromatin values were recorded by determining the area of the interphase nucleus and of chromocenters by planimetry and the heterochromatin values were expressed as percent per nuclear area. Nuclear volume as well as interphase chromosome volume along with their somatic chromosome numbers, number of chromocenters and heterochromatin percentage is given in Table 1. The somatic chromosome numbers were found to vary from 12 to 40 . For confirmation, camera lucida drawings of metaphase chromosomes of all the accessions of $C$. dactylon collected from different districts were made very keenly and these are shown in Fig. B (10-28). In the present study, eight among 19 accessions were diploid with $2 n=18$ chromosomes. Only one accession collected from Naogaon was found to be tetraploid with $2 n=4 x=36$ and rest of these were aneuploid showing the chromosome numbers 12 , $14,16,22,24,26,32,40$, etc.
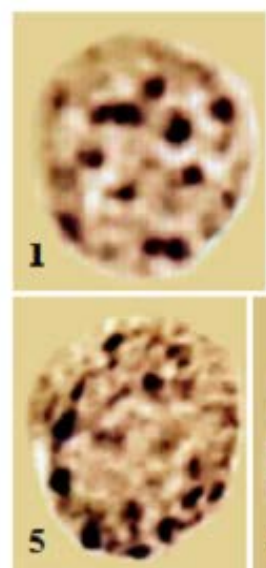

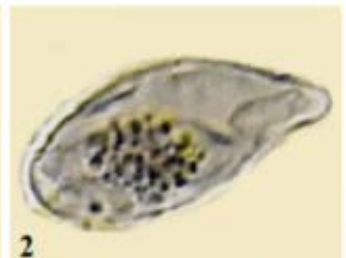

2

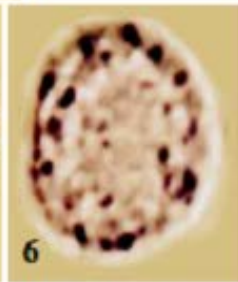

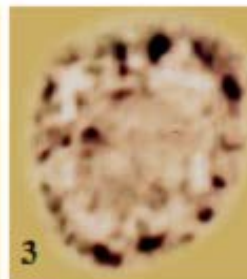
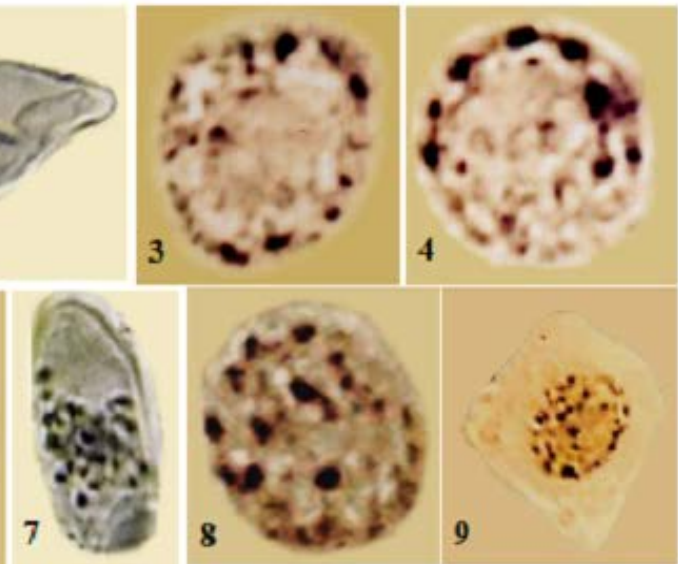

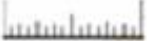

$10 \mu m$

Fig. A (1-9): Representative figures of interphase showing chromocentric structure of nucleus and chromocenters in nine accessions of Cynodon dactylon collected from different habitats. 1 = Lalmonirhat, 2 = Gazipur, 3 = Thakurgaon, $4=$ Shariatpur, $5=$ Barguna, $6=$ Naogaon, $7=$ Jhenaidah, $8=$ Narshingdi, $9=$ Maymensingh . 


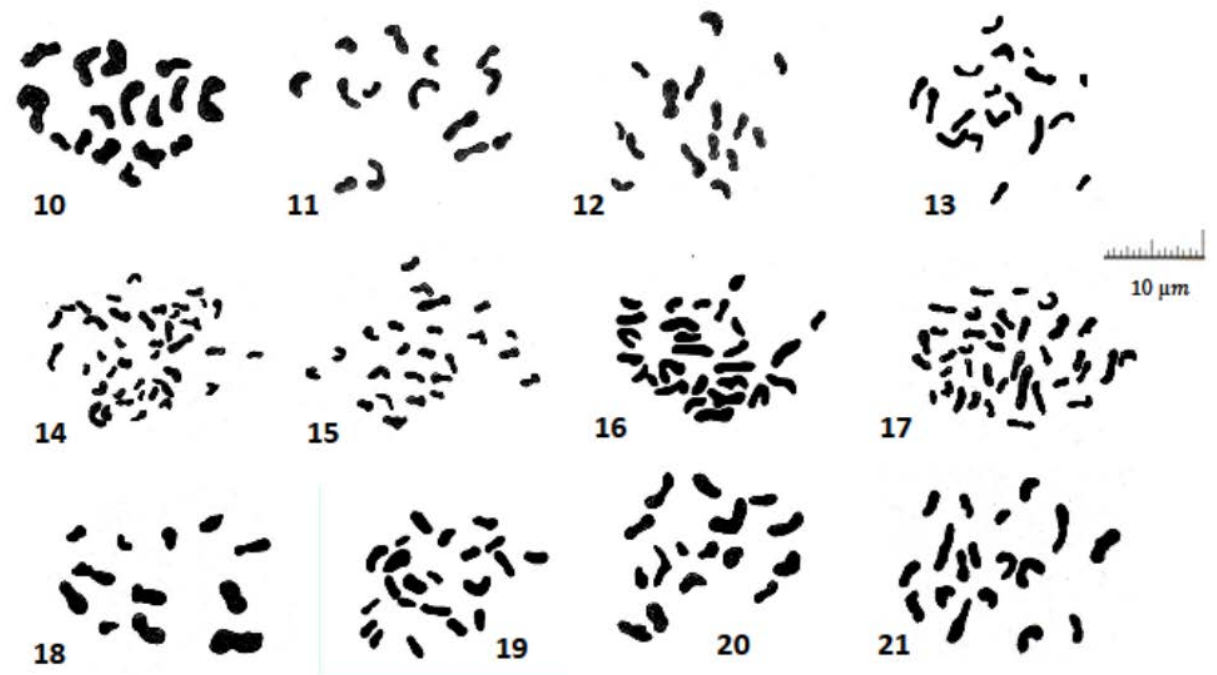

Fig. B (10-21): Camera-lucida drawings of respective chromosome number in 12 accessions of Cynodon dactylon collected from four different zones of Bangladesh. $10=$ Rangpur $(2 \mathrm{n}=18), 11=$ Lalmonirhat, Aneuploidy (14), 12 = Dinajpur $(2 \mathrm{n}=18), 13$ = Thakurgaon $(2 \mathrm{n}=18), 14=$ Panchagarh, Aneuploidy (40), 15 $=$ Gaibandha, Aneuploidy (24), $16=$ Rajshahi, Aneuploidy (26), $17=$ Naogaon $(2 \mathrm{n}=4 \mathrm{x}=36), 18=$ Pabna, Aneuploidy (12), $19=$ Gazipur, Aneuploidy (22), $20=$ Narshingdi, Aneuploidy (16), $21=$ Sherpur $(2 n=18)$.

\section{Contd. Fig. B}

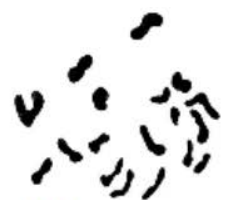

22

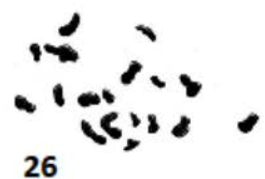

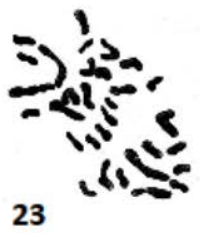

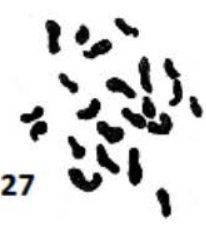

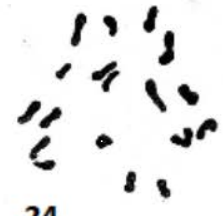

24

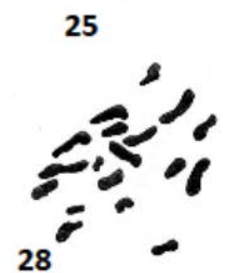

Fig. B (22-28): Camera-lucida drawings of respective chromosome number in 07 accessions of Cynodon dactylon collected from four different zones of Bangladesh. $22=$ Maymensingh, Aneuploidy (32), 23 = Khulna, Aneuploidy (32), $24=$ Jessore $(2 \mathrm{n}=18), 25=$ Jhenaidah $(2 \mathrm{n}=18), 26=$ Faridpur $(2 \mathrm{n}=18), 27$ $=$ Shariaetpur, Aneuploidy (22), $28=$ Barguna $(2 n=18)$ 
Table 1. Number of chromosome, nuclear volume, interphase chromosome volume, number of chromocentres and heterochromatin percentage per nuclear area in different accessions of Cynodon dactylon collected from different districts under different zones of Bangladesh

\begin{tabular}{|c|c|c|c|c|c|c|c|}
\hline 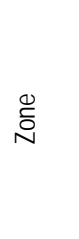 & 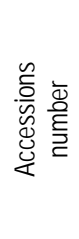 & 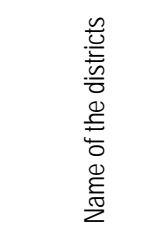 & 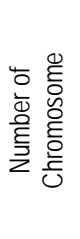 & 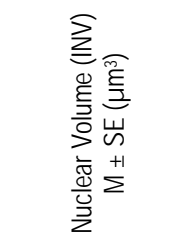 & 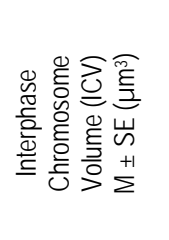 & 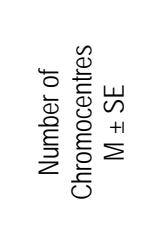 & 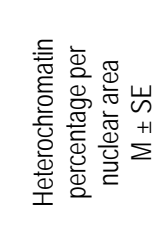 \\
\hline \multirow{6}{*}{ North } & 1. & Rangpur & $18^{*}$ & $2.807 \pm 0.102$ & $0.156 \pm 0.006$ & $14 \pm 0.566$ & $28.675 \pm 1.627$ \\
\hline & 2. & Lalmonirhat & $14^{\star \star}$ & $12.077 \pm 0.093$ & $0.863 \pm 0.007$ & $14 \pm 0.632$ & $51.037 \pm 5.982$ \\
\hline & 3. & Dinajpur & 18 * & $14.354 \pm 0.089$ & $0.797 \pm 0.005$ & $16.4 \pm 0.669$ & $25.548 \pm 1.272$ \\
\hline & 4. & Thakurgaon & $18^{*}$ & $2.706 \pm 0.117$ & $0.150 \pm 0.006$ & $15.2 \pm 1.073$ & $46.661 \pm 3.738$ \\
\hline & 5. & Panchagarh & $40^{\star *}$ & $9.134 \pm 0.152$ & $0.228 \pm 0.004$ & $16.4 \pm 0.877$ & $57.955 \pm 6.537$ \\
\hline & 6. & Gaibandha & $24^{\star \star}$ & $0.674 \pm 0.084$ & $0.028 \pm 0.003$ & $16.6 \pm .358$ & $29.461 \pm 3.547$ \\
\hline \multirow{3}{*}{ West } & 7. & Rajshahi & $26^{* \star}$ & $13.996 \pm 0.154$ & $0.538 \pm 0.006$ & $17 \pm 0.283$ & $29.455 \pm 2.044$ \\
\hline & 8. & Naogaon & $36^{\star \star \star}$ & $3.578 \pm 0.066$ & $0.099 \pm 0.002$ & $16.8 \pm 0.438$ & $24.389 \pm 1.124$ \\
\hline & 9. & Pabna & $12^{* \star}$ & $4.620 \pm 0.088$ & $0.385 \pm 0.007$ & $11.4 \pm .219$ & $45.185 \pm 7.983$ \\
\hline \multirow{4}{*}{ East } & 10. & Gazipur & $22^{\star \star}$ & $41.921 \pm 0.180$ & $1.905 \pm 0.008$ & $17.6 \pm 0.3578$ & $39.793 \pm 2.242$ \\
\hline & 11. & Narshingdi & $16^{\star \star}$ & $17.238 \pm 0.295$ & $1.077 \pm 0.018$ & $15.2 \pm .715$ & $33.82 \pm 6.588$ \\
\hline & 12. & Sherpur & $18^{*}$ & $5.209 \pm 0.093$ & $0.289 \pm 0.005$ & $17.6 \pm 0.358$ & $38.706 \pm 5.132$ \\
\hline & 13. & Mymensingh & $20^{* *}$ & $0.862 \pm 0.084$ & $0.043 \pm 0.004$ & $13 \pm 0.707$ & $41.782 \pm 1.033$ \\
\hline \multirow{6}{*}{ South } & 14. & Khulna & $32^{\star *}$ & $5.057 \pm 0.09$ & $0.158 \pm 0.003$ & $16 \pm 0.80$ & $30.048 \pm 5.094$ \\
\hline & 15. & Jessore & $18^{*}$ & $5.058 \pm 0.171$ & $0.281 \pm 0.004$ & $16.4 \pm 1.043$ & $47.653 \pm 1.411$ \\
\hline & 16. & Jhenaidah & $18^{*}$ & $11.811 \pm 0.150$ & $0.656 \pm 0.008$ & $17.40 \pm .358$ & $19.759 \pm 2.714$ \\
\hline & 17. & Faridpur & $18^{*}$ & $1.348 \pm 0.105$ & $0.075 \pm 0.006$ & $17.6 \pm 0.358$ & $30.304 \pm 5.303$ \\
\hline & 18. & Shariatpur & $22^{\star \star}$ & $13.183 \pm 0.089$ & $0.599 \pm 0.004$ & $14.4 \pm 1.431$ & $66.022 \pm 5.481$ \\
\hline & 19. & Barguna & $18^{*}$ & $29.886 \pm 0.097$ & $1.660 \pm 0.005$ & $14.4 \pm 1.189$ & $65.286 \pm 7.938$ \\
\hline
\end{tabular}

*= Diploid chromosome number, ${ }^{* *}=$ Aneuploid, ${ }^{* \star *}=$ Tetraploid 


\section{Discussion}

In the present experiment, interphase nuclei of different accessions of $C$. dactylon were found to be chromocentric. Joshi and Ranjekar (1983) and Patankar and Ranjekar (1984) found similar type of chromocentric nuclear organization in Phaseolus species. The number of chromocenters was always less compared to that of their chromosome numbers. The values ranged from 11.4 (Acc.9) to 17.60 (Acc.10, Acc.12 and Acc.17). The chromocentric number did not correlate with the somatic chromosome numbers of the diploid, tetraploid or aneuploid accession. Kabir (1993) reported more or less same number of chromocenter in six Crotalaria species. The reduction in number of chromocenters might be due to fusion or overlapping of chromocenters indicating the somatic association of chromosomes (Kabir and Singh 1989). Dayal and Prasad (1983) stated that the number of chromocenters is considered to be controlled genetically and is, therefore a species specific character.

In case of heterochromatin percentage per nuclear area the values obtained in this study were highly variable. The values ranged from $19.759 \%$ (Acc.16) to 66.022 (Acc.18). In this study, higher percentage of heterochromatin might be due to the presence of different classes of heterochromatin (Vosa1970 and La Cour 1978). HCl-Giemsa banding is also known to visualize most of the types of heterochromatin on chromosome (Joshi and Ranjekar 1982). The variable result in the present investigation might be due to the fact that $\mathrm{HCl}$-haematoxylin banding revealed more than one class of heterochromatin in interphase chromosomes. Lafontaine (1974), Nagl and Fusenig (1979) stated that chromocentric nuclear organization is assumed to be governed by small size of chromosomes and low DNA content. This holds partially true for all the accessions of $C$. dactylon which showed very small size of chromosomes.

Yamakawa and Sparrow (1965 and 1966) studied interphase chromosome volume as a reliable index of radio sensitivity in plants and their work established a positive linear correlation between radiation sensitivity and chromosome volume in plant cells. In present study this parameter (interphase chromosome volume) was considered since all the accessions of $\boldsymbol{C}$. dactylon were collect from different ecological conditions, where the temperature as well as radiation index may vary from one zone to another. In this study, the interphase chromosome volume $\left(1.905 \mu \mathrm{m}^{3}\right)$ was found in the accession collected from Gazipur and the lowest value $\left(0.028 \mu \mathrm{m}^{3}\right)$ was found in the accession collected from Gaibandha. This character was not correlated with chromosome number. Thus, it may be said that increase or decrease of interphase chromosome volume may be caused due to alteration of cell membrane configurations, modification of chromosomal volume and changes in sensitivity to physical or chemical factors, functioning always in the environment. Yamakawa and Sparow (1966) reported increase in mutation rate per roentgen in higher plants and that was highly correlated with increase in both ICV (interphase chromosome volume) and DNA content per chromosome.

In present study the most striking feature of $C$. dactylon was found in case of chromosome number. Range of chromosome number was really surprising when the basic chromosome number is considered to be $x=9$ (Forbes and Burton 1963, Clayton and Harlan 1970). In this experiment only 08 (eight) accessions out of 19 were found to be diploid $(2 n=18)$. Only one was found to be tetraploid and rest of them were aneuploid. De 
Silva and Snaydon (1995) stated that most populations contained only tetraploid plants $(2 n=36)$, but populations from roadsides and lawns in the wet region and from forest in the hill country contained only diploids plants $(2 n=18)$. They also said that soil acidity seems to be the main factor determining the distributions of the cytotypes. They did not report any triploid or any aneuploid. On the contrary Dhaliwal et al. (2018) reported Cynodon dactylon with the basic chromosome number of $n=8$, while few other reports on five different cytotypes with basic chromosome number $n=8, n=9$ and $n=18$ have been reported in his literature based on works of several investigators (Gupta and Srivastava 1970, Kumar and Sachdeva 1988, Malik and Tripathi 1968, Sachdeva and Bhatia 1980, Sinha et al. 1990). However, the present findings may be supported by Federov (1974), Christopher and Abraham (1974), Brown (1950) and Hurcombe (1947). Gupta and Shrivastava $(1970)$ reported one diploid $(2 n=18)$ and three triploid $(2 n=27)$ collections of $C$. dactylon. Chiavegatto et al. (2016) aimed to determine the karyotype asymmetry index among accessions of Cynodon to discriminate them. They ultimately reported two diploid, one triploid, four tetraploid and one pentaploid accession. Their findings indicated predominant level of ploidy for the tetraploid accessions. Along with their findings on chromosome counts, it may be said that there is a wide genetic variability which is very important for origin, evolution and development of plant species. The preponderance of aneuploidy observed in the present study throws light on the evolutionary tendencies which might go hand to hand in the phylogenetic evolution due their different adaptive values. When one of the characters might put a type or accession of $C$. dactylon at highest level of advancement then the others may be still in original stage. However, aneuploids play an important role in the breeding programme and thus, the main objective of forage breeding programme may be an important way to obtain those genotypes with desirable agronomic traits.

\section{Acknowledgement}

The cytological part of this research work has been carried out at Prof. S. Alam Cytogenetics Laboratory, Dept. of Botany, University of Rajshahi, Bangladesh and Chairman of the same Department is gratefully acknowledged for providing laboratory support of this work.

\section{References}

Brown WV (1950). A cytological study of some Texas gramineae. Bull. Torrey Bot. Club, 77: 63-76.

Chiavegatto RB, Paula CMP, Sobrinho FS, Benites FRG and Techio VH (2016). Karyotype asymmetry in Cynodon Rich. (Poaceae) accessions. Genetic and Molecular Research, 15(4): 15049152.

Christopher J and Abraham A (1974). Studies in the cytology and phylogeny of south Indian. Grasses II sub-family eragrostoideae. Cytologia, 39: 561-571.

Clayton WD and Harlan JR (1970). The genus Cynodon L. C. Rich in tropical Africa. Kew Bulletin, 24: 185-189.

Dayal N and Prasad C (1983). Genetic regulation of chromocentres in radish. Raphanus sativus L. Cytologia, 48: 245252.

De Lima JA and Vilela D (2005). Formacao e manejo de pastagens de Cynodon. In: Cynodon: Forrageiras que estao revolucionando a pecuaria Brasileira (Vilela D, Resende JC \& De Lima J. eds). Embrapa Gado de Leite, pp. 11-32.

De Silva PHAU and Snaydon RW (1995). Chromosome number in Cynodon dactylon in relation to ecological conditions. Ann. Bot., 76: 535-537. 
Dhaliwal A, Kour N and Gupta RC (2018). Cytology of some grasses from Haryana and Shiwalik Hills. Cytologia, 83(1): 23-30.

Dhaliwal ARS and Gupta RC (2011). Cytological study on three cytotypes of Bermuda grass (Cynodon dactylon (L.) Pers.) from Haryana and Shiwalik hills. Int. J. Basic Appl. Biol., 5: 7-12.

Dunne JC, Tuong TD, Livingston DP, Reynolds WC and Milla-Lewis SR (2019). Field and laboratory evaluation of bermudagrass germplasm for cold hardiness and freezing tolerance. Crop Sci., 59: 392-399.

Federov (1974). Chromosome numbers of flowering plants; Otto Koeltz Sc. Publ. West Germany. pp. 518.

Forbes I and Burton GW (1963). Chromosome numbers and meiosis in some Cynodon species and hybrids. Crop Science, 3: 75-79.

Gupta PK and Srivastava AK (1970). Natural triploidy in Cynodon dactylon (L.) Pers. Caryologia, 23: 29-35.

Haque A, Ali MA, Waxuddin M and Khan MA (1976). Squash method for the mitotic chromosomes of grasses. Curr. Sci., 45: 382-383.

Harlan JR, de Wet JMJ, Rawal KM, Felder MR and Richardson WL (1970). Cytogenetic studies in Cynodon L.C. Rich. (Gramineae). Crop Sci., 10: 288-291.

Huang C, Liu G, Bai C and Wang W (2014). Genetic analysis of 430 Chinese Cynodon dactylon accessions using sequence-related amplified polymorphism markers. International Journal of Molecular Sciences, 15: 19134-19146.

Hunter AWS (1934). A karyosystematic investigation in the Gramineae. Canadian Journal of Research, 11: 213-241.

Hurcombe R (1947). A cytological and morphological study of cultivated Cynodon species. Journal of South African Botany, 13: 107-116.

Joshi CP and Ranjekar PK (1982). Visualization and distribution of heterochromatin in interphase nuclei of several plant species as revealed by a new Giemsa banding technique. Cytologia, 47: 471- 480.

Joshi CP and Ranjekar PK (1983). Mechanism of HCl-Giemsa banding technique. Nucleus, 26: 35-48.

Kabir G (1993). Interphase nuclear structure and heterochromatin in six species Crotalaria. Bangladesh J. Bot., 22(2): 155-160.

Kabir G and Sing RM (1989). Interphase nuclear structure and heterochromatin in Cicer species. Cytologia, 54: 27-32.

Kumar P and Sachdeva SK (1988). Karyomorphological observations and biochemical variability in triploids of Cynodon dactylon (L.) Pers. complex. Proc. Indian Sci. Congr. Assoc., 75: 210-211.

La Cour LF (1978). Two types of constitutive heterochromatin in the chromosomes of some Fritillaria species. Chromosoma, 67: 67-76.

Lafontaine JG (1974). Ultrastructural organization in plant cell nuclei; In: The Cell Nucleus, H Busch (ed.), Academic Press, New York, London, Vol. I pp. 149-185.

Malik CP and Tripathi RC (1968). Cytological evolution within the Cynodon dactylon complex. Biol. Zent., 87: 625-627.

Moffett AA and Hurcombe R (1948). Chromosome numbers of South African grasses. Heredity, 3: 369-373.

Nagl W and Fusenig HP (1979). Types of chromatin organization in plant nuclei. Plant Sys. Evol. Suppl., 2: 221-233.

Nayar GG, George KP and Gopal-Ayengeer AR (1971). The relation between cytological abnormalities and interphase chromosome volume in plants growing in a high radiation area. Radiation Bot., 11: 175-178.

Parvin N (2002). A Cytomorphological study on five types of Cynodon dactylon L. MSc Thesis. Department of Botany, Rajshahi University, Rajshahi. 
Patankar S and Ranjekar PK (1984). Interphase nuclear structure and heterochromatin in Phaseolus plant species. Plant Cell Rep., 3: 130-133.

Pedreira CGS (1996). Avaliacao de novas gramineas de genero Cynodon para a pecuaria dos Estados Unidos. In: Workshop Sobreo potencial forrageiro do genero Cynodon, Embrapa Gado de Leita, pp. 111-125.

Rochecouste E (1962). Studies on the biotypes of Cynodon dactylon (L.) Pers. I Botanical investigations. Weed Research, 2: 1-23.

Sachdeva SK and Bhatia MS (1980). Chemotaxonomic studies in Cynodon dactylon (L.) Pers. complex II. Flavonoid patterns and ascorbic acid content. Proc. Indian Acad. Sci. (Plant Sci.), 89(3): 193-196.

Sinha RRP, Bhardwaj AK and Singh RK (1990). SOCGI plant chromosome number reports IX. Journal of Cytol Genet., 25: $140-143$.

Vosa CG (1970). Heterochromatin recognition with fluorochromes. Chromosoma, 30: 366-372.

Wu Y and Taliaferro CM (2009). Bermuda grass. In: Genetic resources, chromosome engineering and crop improvement. (Forage crops) (Singh RJ, ed.). CRC Press, New York, Vol. 5, pp. 289.

Yamakawa K and Sparrow AH (1965). Correlation of interphase chromosome volume and reduction of viable seed set by chronic gamma irradiation of 21 cultivated plants during reproductive stages. Radiation Botany, 5: 557-565.

Yamakawa K and Sparrow AH (1966). Correlation of interphase chromosome volume with pollen abortion induced by chronic gamma irradiation of interphase chromosome volume with pollen abortion induced by chronic gamma irradiation of 21 cultivated plants during reproductive stages. Radiation Botany, 6: 21-28.

Zheng Y, Xu S, Liu J, Zhao Y and Liu J (2017). Genetic diversity and population structure of Chinese natural bermudagrass [Cynodon dactylon (L.) Pers.] germplasm based on SRAP markers. PLoS ONE, 12(5): e0177508.

Zhi-Yun G, Chao X, Ming-Liang Z and Miao W (2013). Distribution of rDNA loci and genome differentiation in tetraploid Cynodon. Indian J. Genet. Plant Breeding, 73: 459-461.

(Manuscript received on September 27, 2018 and revised on March 05 2019) 